\title{
QUANDO A CIDADE É OBJETO DE PESQUISA
}

\section{Delia Dutra da Silveira*}

LEPETIT, Bernard; TOPALOV, Christian. La ville des sciences sociales. Paris: Belin, 2001. 409p.

Foi na cidade de Paris, em 1989, que dois professores da École de Hautes Études em Sciences Sociales (EHESS), Bernard Lepetit e Christian Topalov, começam a organizar um seminário ao qual denominaram "La ville de sciences sociales". Preocupava-os o estudo e o debate sobre as representações científicas da cidade, pois para eles nas ciências sociais as modalidades de construção da cidade como objeto de ciência variam profundamente. ${ }^{1}$ Durante os períodos 1995-1996 e 1996-1997, eles convidaram pesquisadores de diversas disciplinas para participarem do seminário, propondo a cada um assumir a discussão da obra de um autor considerada fundamental para os estudos da cidade, la ville. Era uma idéia comum de Lepetit e Topalov publicar um livro como resultado desse trabalho em colaboração com os pesquisadores convidados, idéia que finalmente se materializou em 2001, apesar do falecimento de Bernard Lepetit em 1996.

La ville des sciences sociales é o resultado desse trabalho conjunto onde entram em cena nove pesquisadores para analisar a obra

\footnotetext{
* Aluna especial da disciplina Cidade e Sociabilidade Urbana, no curso de Doutorado em Sociologia da Universidade de Brasília (UnB); pesquisadora-colaboradora do Centro Scalabriniano de Estudos Migratórios (CSEM) de Brasília; mestre em Ciências da Comunicação pela Universidade do Vale do Rio dos Sinos (Unisinos).E-mail: deliadutra@ gmail.com
} 
de um autor cujo referente comum é a problemática urbana. Levando em conta a abrangência deste empreendimento, considerando que estamos perante um livro que refere a tantos outros, faremos aqui a nossa navegação seguindo a ordem proposta pelos capítulos.

Maurice Halbwachs, sua obra e as suas marcas, são objeto do primeiro capítulo escrito por Christian Topalov, ${ }^{2}$ que explicita como sendo resultado de uma pesquisa onde ele visava esclarecer a construção do objeto "cidade" em Halbwachs, partindo basicamente de dois documentos fundamentais: o livro resultado da tese de doutorado que Halbwachs defendeu com 32 anos, em 1909, intitulada Les expropriations et le prix des terrains à Paris (1860-1900), e uma brochura publicada em 1908, La politique foncière des municipalités, a número três da coleção "Les Cahiers du Socialiste".

Topalov analisa questões instigantes para a compreensão do pensamento de Halbwachs e que, já na época, se levantavam a propósito dessas duas publicações: por que um professor de filosofia e membro da "escola de sociologia", escreve uma tese para a Faculdade de Direito sobre a história dos terrenos em Paris?; qual o lugar em que o autor pretende se colocar na topografia das disciplinas e de que tipo de estudo dos fenômenos urbanos pode se tratar?; finalmente, que "socialista" é esse "sociólogo" cujo trabalho nos ensina as relações entre socialismo e "urbanismo", disciplina que está nascendo?

Questões reveladoras que ajudam a melhor compreender sua obra, seu lado de sociólogo e seu lado de militante, mas não sem antes Topalov nos introduzir num contexto de produção em que Halbwachs acabou sendo considerado a maior figura da denominada "segunda idade do durkheimismo" e, para alguns de forma tardia, o precursor da sociologia urbana francesa. Além da sua proximidade ao pensamento de Durkheim e de Simiand, pode-se encontrar nele influências de pensadores alemães, país onde esteve pesquisando 
como bolsista em duas oportunidades. Destaca-se, também, a importância do seu estágio em 1930 no Departamento de Sociologia da Universidade de Chicago, e as posteriores publicações, nos anos 1960, de sociólogos americanos formados pela Escola de Chicago onde reconhecem a estreita afinidade entre a morfologia francesa - na qual se inclui a Halbwachs junto com Durkheim e Mauss e a ecologia humana, assim como a antecipação das hipóteses de Halbwachs sobre crescimento urbano.

Toda essa sorte de reivindicações tão diversas, segundo Topalov, promoveu Halbwachs ao lugar de clássico, etambém, desde os anos 1990 mobilizou o mundo acadêmico de historiadores e sociólogos como o pensador da memória coletiva. Claramente inspirado na proposta durkheimiana, em Les cadres sociaux de la mémoire (1925), Halbwachs demonstra a impossibilidade de conceber o problema da evocação e da localização das lembranças abrindo mão dos quadros sociais reais que servem de pontos de referência nesta reconstrução que chamamos memória. ${ }^{3}$ Em La mémoire collective (1950), seu livro póstumo, o autor defende o caráter social da memória, no sentido de que ela existe em relação a pessoas, momentos, palavras, idéias; isto é, a memória individual conformada a partir de uma memória coletiva demarcada pelo tempo e pelo espaço, entendidos pelo autor como construções sociais seguindo a proposta de Durkheim. De acordo com Topalov, Halbwachs foi um intelectual que só aos 41 anos obteve seu primeiro cargo de professor universitário, porém, ele conseguiu ultrapassar as paredes da universidade para dialogar com o mundo dos urbanistas franceses e dos arquitetos italianos que se interessaram por suas propostas metodológicas para o estudo das cidades.

Die Stadt, texto célebre de Max Weber sobre a cidade, é o objeto de análise no segundo capítulo escrito por Hinnerk Bruhns. ${ }^{4}$ $\mathrm{O}$ autor realiza uma retomada do texto de Weber confrontando-o com o conjunto de comentários e análises que deste vêm se fazendo 
ao longo da sua vida ainda incerta, lembrando que este texto - não datado e publicado um ano depois da morte de Weber - estimase que foi escrito entre 1913-1914. Trata-se de um manuscrito inacabado encontrado pela esposa de Weber e que hoje está perdido, cujas várias publicações posteriores, por exemplo em Economia e Sociedade, foram reproduzindo e até multiplicando alguns erros como resultado dos problemas surgidos ao decifrá-lo, traduzilo, assim como também problemas de redação próprios do texto, considerando que Weber não teria chegado a realizar uma última revisão.

Ancorado no seu profundo conhecimento da obra weberiana, Bruhns adota uma posição bem clara durante todo o capítulo apontando os erros de leituras e de interpretações generalizados de uma obra cuja complexidade dificulta poder delimitá-la a uma única disciplina. $\mathrm{O}$ autor realiza um interessante percurso buscando responder a três questões que, na sua visão, tornam-se essenciais e ajudam a evitar confusões: primeiro, o que nós sabemos da história do texto em si mesmo e das circunstâncias de redação; segundo, qual a função que devemos lhe atribuir no conjunto da obra de Weber e quais as relações com outras partes da sua obra, observando o lugar que nela ocupa a cidade, incluindo a cidade moderna; e, por último, quais os laços com a pesquisa urbana da época de Weber e com os debates contemporâneos sobre a cidade, em particular sobre a cidade medieval.

Passando agora ao terceiro capítulo, Donatella Calabi ${ }^{6}$ propõe um reencontro com Marcel Poëte e sua obra, resgatando a sua importância para a história urbana na França, na Europa e na América Latina. Poëte é para alguns uma espécie de pai fundador do urbanismo historicista e também um dos grandes protagonistas do pensamento europeu do início do século XX em matéria de urbanismo. Contudo, conhecer sua atividade durante os anos da juventude, como bibliotecário, arquivista, organizador de exposições 
e como historiador, torna-se fundamental, segundo Calabi, para medir a originalidade da sua posição tanto no mundo científico quanto o mundo prático-profissional.

Suas duas obras mais referenciadas são: Une vie de cite: Paris de sa naissance à nos jours, quatro volumes publicados entre 1924 e 1931, e Introduction à l'urbanisme : l'évolution des villes, publicado em 1929, no qual o autor vai definir o urbanismo como ciência da observação - ele defendia a necessidade do contato direto com o objeto de estudo. Seu ponto de partida conceitual em Une vie de cité é a cidade hoje; nela Poëte busca descobrir os traços do passado, salientando especialmente o quarto volume, pela sua abordagem original para a época, onde ele se centra na análise de uma iconografia extremamente rica.

A autora dá uma ênfase especial ao trabalho crítico do qual Poëte foi objeto e os ciclos pelos quais vem passando sua obra, isso como uma porta de entrada à compreensão da dimensão da obra do autor. Nessa linha, ela identifica três ondas sucessivas de estudos e interpretação: uma primeira como aquela de um Poëte pioneiro do "urbanismo" na França e para além de suas fronteiras, notadamente a Argélia e a América Latina; uma segunda como iniciador da análise urbana, tendo muito eco nos anos sessenta entre arquitetos italianos e do resto da Europa, denominando a sua contribuição teórica de "geografia urbana"; e, uma terceira e última onda nos anos oitenta, onde Poëte é resgatado no âmbito da historiografia do urbanismo francês.

The Ghetto, tese de doutorado em Sociologia defendida em 1926 por Louis Wirth na Universidade de Chicago, é o tema central do capítulo quatro onde Catherine Rhein ${ }^{6}$ enriquece a análise desta obra - publicada pela primeira vez em 1928 aprofundando os principais elementos do contexto social, econômico e político no seio do qual Wirth a escreveu. Logo, concentra-se na apresentação 
crítica do livro para encerrar analisando as condições e formas de recepção desta obra que, de acordo com Rhein, amiúde é julgada como sendo menor por causa de leituras rápidas e completamente descontextualizadas; porém, ela está sendo constantemente reeditada e referenciada.

Wirth na sua tese determina por objeto o gueto como instituição e como forma urbana e social; ele pesquisa sobre sua formação e institucionalização na Europa cristã, e logo sobre sua transplantação para as cidades do Novo Mundo. No entanto, sua obra transcende pela sua tese sobre o judaísmo, sua história e o seu porvir assim com também, pelo seu artigo $O$ urbanismo como modo de vida, publicado em 1938 e atualmente considerado essencial para os estudos da problemática urbana. Nele o autor desenvolve uma teoria sociológica e sociopsicológica do urbanismo ${ }^{7}$ com o intuito de construir um referencial de análise que, por momentos, se inspira e dialoga com a proposta de Simmel, sobre a "metrópole e a vida mental", e com a de Park e as suas "sugestões para a investigação" da problemática urbana. Para Wirth o modo de vida urbano ultrapassa os limites da própria cidade, por ele definida como "um núcleo relativamente grande, denso e permanente, de indivíduos socialmente heterogêneos". ${ }^{8}$

Falar em Wirth e no seu contexto de produção implica desvendar os bastidores do trabalho desenvolvido pelos docentes e estudantes da denominada "Escola de Chicago", as suas pesquisas de caráter monográfico e geralmente subordinadas às demandas das autoridades da época, assim como o contexto político no início de século numa sociedade onde correntes como o anti-semitismo e o anticomunismo se instalaram com força. Elementos esses que nos ajudam a compreender o porquê da centralidade nestas pesquisas de questões relacionadas ao acelerado processo de urbanização das metrópoles norte-americanas, e nos ajudam a compreender os contornos, interesses e silêncios aparentes da Sociologia de Chicago. 
Implica, também, reconhecer neles as influências do pensamento europeu, pois muitos auatores que o influenciaram formaram-se na Alemanha com Weber e Simmel, e o seu diálogo com as origens da sociologia urbana francesa. De acordo com Rhein, a verdadeira recepção desta obra nas ciências sociais francesas se produz quando as questões ligadas à imigração e ao "risco do gueto" chegaram na agenda política no início dos anos 1980.

Marie-Claire Robic ${ }^{9}$, autora do capítulo cinco, busca compreender em que condições gerais acontece a emergência da análise que realizou Walter Christaller ao desenvolver sua conhecida teoria dos "lugares centrais", apresentada no livro Die zentralen Orte in Süddeutschland, publicado em 1933. Clássico da geografia urbana contemporânea, produto da sua tese de doutorado, este livro somente foi consagrado uns trinta anos após a sua publicação; várias são as razões desta consagração tardia, mas haveria uma razão principal vinculada à pessoa de Christaller, não à sua teoria em si mesma, pela sua vinculação a instituições do regime nazista.

O livro se desenvolve em quatro momentos: um primeiro onde se expõe a fundamentação teórica de uma geografia das cidades; um segundo que propõe articular teoria e um conjunto observável de cidades; um terceiro de caráter "regional", no qual descreve em detalhe diversos "sistemas" de cidades que estuda na Alemanha do Sul; e um quatro onde conclui com uma "verificação da teoria" a partir de resultados obtidos e os "resultados metodológicos" para a geografia do povoamento, apontando para a pertinência do método econômico. Christaller é considerado o "padrinho" da new geography, movimento dos geógrafos anglo-americanos que defendem a vontade de teorização e construção de uma nova problemática geográfica que substituiria a problemática do 'espaço' e do 'lugar' da geografia clássica, trazendo a teoria dos lugares centrais como paradigma principal do movimento. 
Paul-André Rosental e Isabelle Couzon, ${ }^{10}$ apresentam o capítulo dedicado ao chamado 'historiador das populações', Louis Chevalier e ao seu clássico Classes laborieuses et classes dangereuses, publicado em Paris em 1958. Obra qualificada de insólita e inclassificável, única no seu gênero e rapidamente concebida como um clássico da história urbana de Paris, apesar de algumas críticas duras provenientes de nomes consagrados na academia.

Os autores advertem sobre o perigo de ficar restrito a Classes laborieuses quando se quer apreender o pensamento de Chevalier; trata-se de uma obra inovadora em que o autor assume o risco de dar conta da articulação entre história, literatura e estatística, algo julgado como inconciliável pela historiografia do século XX. À sua formação de historiador, ele se esforça por acrescentar a de demógrafo, disciplina cujo processo de institucionalização ele acompanha na França.

O seu objeto de pesquisa privilegiado é provavelmente a repartição da população e sua evolução temporal sob o efeito das migrações. Ele considera a França como um mosaico de pequenos países, apontando para a relevância do estudo da psicologia dos povos, elemento que, de acordo com Rosental e Couzon, aparece ao longo da sua obra como princípio explicativo indubitável, sem por isso se transformar em determinista. Em síntese, a marca pessoal da obra de Chevalier seria o lugar de centralidade dado ao estudo da migração e, mais geralmente, às dinâmicas dos fenômenos sociais, servindo-se para isso do recurso de combinação de fontes quantitativas e qualitativas, todas convergindo para construção de um mesmo objeto.

Dominique Lorrain ${ }^{11}$ faz uma retomada crítica e detalhada do livro de Manuel Castells e Francis Godard: Monopolville, publicado em 1974, hoje praticamente esquecido e que foi, nos anos 1970, um emblema da Sociologia Urbana Marxista da França. O livro 
estuda o caso de uma cidade, Dunkerque, e sua organização a partir da transformação radical da base produtiva. Aborda-se a função do Estado na produção urbana e sustenta-se a tese da sua estreita articulação aos interesses do capital monopolista. Os pesquisadores buscaram elucidar as contradições que os planejadores da época não souberam prever, fazendo emergir a complexidade de uma realidade social que não dava conta dos planos, explica Lorrain, que para realizar sua análise, parte da seguinte pergunta: qual é, então, a contribuição de Monopolville ao pensamento sobre a cidade? Para se dar conta do livro de forma equilibrada e, assim, tentar responder a tal provocação, ele fará um percurso pelo projeto que o engendra, o conteúdo e os seus limites.

O livro foi o resultado de uma pesquisa financiada diretamente pelo Estado. Seus críticos apontam para o problema de ele ter se transformado mais num projeto militante do que científico: a dificuldade está na mistura permanente entre o trabalho empírico e uma retomada ideológica onde interpretação não se articula com o material levantado, explica Lorrain. Poder-se-ia falar num excesso de ortodoxia que buscou articular um projeto de pesquisa científica com uma reflexão político-militante, às vezes cheio de trivialidades falsamente teóricas, segundo Lorrain, fazendo-o extremamente velho no seu estilo e que apenas atingidos os resultados, logo eles foram criticados como ultrapassados.

Os autores do livro hoje estão por caminhos bem diferentes ao que transitaram em Monopolville. Castells partiu, logo na época, para os Estados Unidos, entorno que contribuiu para mudanças no seu pensamento, agora menos estruturalista e para quem já não mais o marxismo daria conta de explicar tudo; e Godard passou logo depois a se interessar pos estudos das práticas sociais, estudando modos de vida, o consumo, a família. No entanto, resulta interessante o capítulo como proposta de retomada de contato com uma obra representativa de uma corrente que ficou conhecida fora da França como "a nova Sociologia Urbana Marxista francesa". 
Jean-Claude Perrot é autor apresentado por Isabelle Backouche $^{12}$ no último capítulo deste livro, onde analisa sua obra Genèse d'une ville moderne: Caen au XVIII siècle, publicada em 1975 na França, produto da sua tese de doutorado. A autora propõe realizar o percurso em duas direções: primeiro, a análise do texto levantando neste ponto a complexidade do objeto devido à sua posição na historiografia dos anos 1960-1970 e à ambição do projeto e do seu método; segundo, a autora discute sobre a diversidade de leitores do livro como elemento que viria a colocar em cena a questão da evolução da história urbana, campo ainda mal definido, e sobre a posição intelectual e institucional de Perrot após a publicação da sua tese.

$\mathrm{Na}$ sua pesquisa sobre Caen, Perrot demonstra uma grande preocupação com a construção do objeto na historiografia urbana, partindo da constatação de que esta disciplina, privilegiando a análise estética das formas, esquece a observação da vida cotidiana, abandonando-a para outras ciências sociais, como a Sociologia, a Ecologia ou a Economia. Sua ambição primeira é a construção do objeto cidade partindo para pesquisa do objeto já construído pelos homens do passado, interessando-se nas modalidades de construção do discurso sobre a cidade onde procura compreender quem fez a cidade e por quê. Logo, ele vai estabelecer um diálogo com a fase da urbanização contemporânea da cidade.

Perrot renuncia a levar adiante um projeto de uma 'história total', que marcava toda uma geração de historiadores, colocando a cidade mais do lado do método do que do objeto. Para Backouche a promoção do objeto urbano não é mais do que uma manifestação particular e pontual de uma reflexão epistemológica sobre o trabalho do historiador, mostrando o caminho da ruptura com a história econômica e social de pós-guerra.

Para encerrar o livro, Topalov reconhece que a motivação desta publicação não gira em torno de pesquisas centradas num único 
problema, uma época, uma escola ou um autor. O livro é um convite a nos determos sobre obras singulares, sobre objetos particulares e em momentos históricos específicos e bem diversos. Poderíamos falar numa metanarrativa, no sentido de em cada capítulo um pesquisador contemporâneo toma a palavra e 'navega' pela obra de um outro que o precede. Essas navegações assumem formas particulares que, no dizer de Topalov, não propõem mais do que interpretações que dão seguimento a muitas outras e que não serão, certamente, as últimas.

\section{Notas}

1 Lepetit; B.; Topalov, C. La ville des sciences sociales. Paris: Belin, 2001.p. 7.

2 Maurice Halbwachs et les Villes - Les expropriations et le prix des terrains à Paris (1909). p.11-45.

3 Duvignaud, Jean. Prefácio. In: Halbwachs, M. A memória coletiva. São Paulo: Vértice, 1990. p.9-10.

4 La ville bourgeoise et l'émergence du capitalisme moderne: Max Weber - Die Stadt (1913/14-1921). p.47-78.

5 Marcel Poëte: pionnier de l'urbanisme, militant de l'histoire des villes - Une vie de cité (1924-1931). p.79-109.

6 Le ghetto de Louis Wirth: forme urbaine, institution et système social - The Ghetto (1928). p.111-149.

7 Velho, Otávio G. (Org.). O fenômeno urbano. Rio de Janeiro: Zahar, 1979. p.8.

8 Idem, p.96.

9 Walter Christaller et la théorie des 'lieux centraux' - Die zentralen Orte in Süddeutschland (1933). p.151-189.

10 Le Paris dangereux de Louis Chevalier: un projet d'histoire utile-Classes laborieuses et classes dangereuses (1958). p.191-226. 
772 Delia Dutra da Silveira

11 Un livre extrême, Manuel Castells et Francis Godard - Monopolville (1974). p.227-266.

12 À la recherche de l'histoire urbaine: Jean-Claude Perrot - Genèse d'une ville moderne (1975). p.267-305. 